\title{
Comparison of creep of the cement pastes included fly ash
}

\author{
Pavel Padevět ${ }^{1, *}$ and Petr Bittnar ${ }^{1}$ \\ ${ }^{1} \mathrm{CTU}$ in Prague, Faculty of Civil Engineering, Thakurova 7, Prague 6, 166 29, Czech Republic
}

\begin{abstract}
The paper is devoted to comparison of creep of cement pastes containing fly ash admixture. The size of creep in time depends on the amount of components of the cement paste. Attention is paid to the content of classical fly ash in cement paste and its impact on the size of creep. The moisture of cement pastes is distinguished because it significantly affects the rheological properties of the material.
\end{abstract}

\section{Introduction}

The size of creep of cement pastes among the properties of materials used in the design of building structures. Cement pastes are the basic parts of a composite called concrete. Of course, the concrete also contains ingredients sand and gravel. But the basis is the same, a mixture of cement and water.

The properties of the cement paste can be influenced by additives and admixtures [1]. This paper deals with a mixture containing fly ash. The fly ash in cement paste causes secondary hydration. Lowers the bulk density can vary the mechanical properties and also can affect the size and development of creep.

Production of ash from coal-fired power plants in the Czech Republic is high against production in other countries. The fly ash is formed in the combustion of coal. The fly ash is not considered as a waste today but as raw material which is use for example in the construction industry. Type of fly ash affects the properties of the concrete, as well. The fly ash which is generated in low-temperature combustion of coal is not in our angle of interest because its $\mathrm{SO}_{3}$ content adversely affects the material properties of the concrete over time. Conversely, the ash which is formed during high temperature combustion of coal is suitable for use in concrete. Such fly ash is called classical. Therefore, this work is dedicated to measuring of creep of the cement pastes containing classical fly ash.

The addition of fly ash to cement or concrete is one of the possible uses. Amount of fly ash affects the rate of increase of the concrete strength and the amount of generated heat of hydration in concrete.

The concrete containing fly ash has a slower evolution of hydration heat [2]. This beneficial effect is preferably applied in massive structures. Evolution of compression strength of concrete with fly ash is slower. Structures which do not require high strength at

\footnotetext{
${ }^{*}$ Corresponding author: pavel.padevet@,fsv.cvut.cz
} 
the beginning it is possible to suitably realize from concrete containing fly ash. How affect the content of fly ash in cement paste the size of creep, attempts to answer this paper.

\section{Measurement of creep}

Measurements are carried out on small specimens measuring $70 \mathrm{~mm}$ in length and $10 \mathrm{~mm}$ diameter. Bodies had the shape of cylinder. Small specimens are suitable for measurement of creep and shrinkage in the test apparatus. Measurements are taken in lever mechanisms, which are always equipped with three optoelectronic gauges of deformation.

The article presents a comparison of these mixtures:

$$
\begin{array}{ll}
\text { - } & 50: 50 \\
\text { - } & 60: 40 \\
\text { - } & 70: 30 \\
\text { - } & 100: 0
\end{array}
$$

Where, the first number represents the content of cement, and the second one expresses content of fly ash in the mixture. The ratio expresses the weight representation of both parts. Water ratio of mixture was 0.4. It is defined as the ratio between weight of water and cement. Fly ash is not considered in water-cement ratio is considered as filler. The mixtures were prepared from Portland cement CEM I 42.5 R.

All experiments were carries out in one year age after production. All sets were consisted of six specimens. Sets of bodies with a content of fly ash contained 4 samples of dried, and 2 samples water saturated. Set of specimens without content of fly ash contained 3 samples of dried and 3 samples saturated.

The drying process had length 24 hours at the temperature $105^{\circ} \mathrm{C}$. Water saturated specimens were stored in water basin for 24 hours, too. The length measurement was usually between 25-30 days.
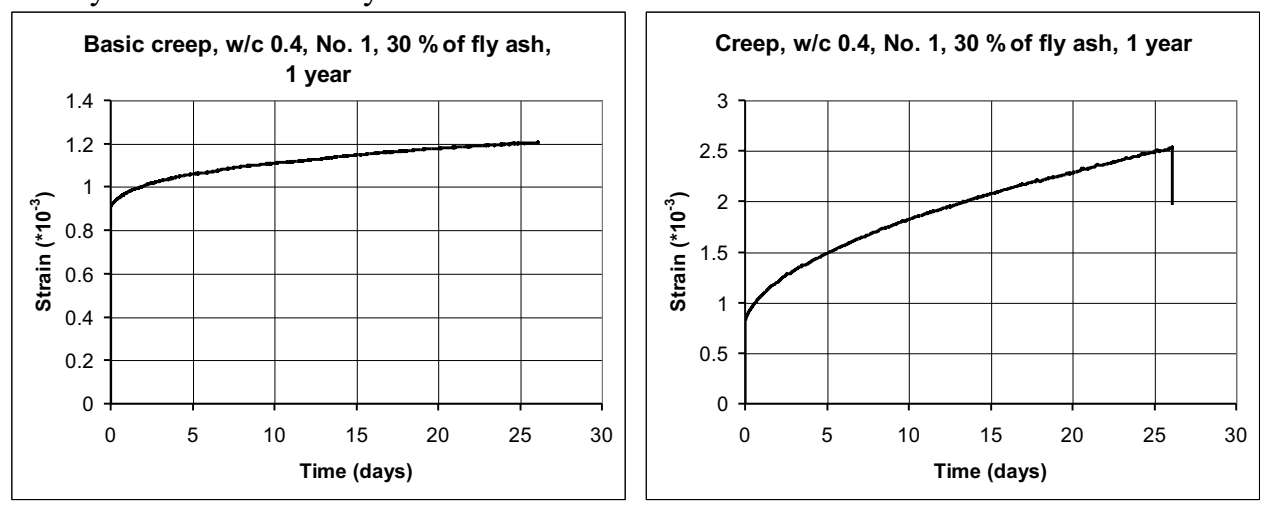

Fig. 1. Graphs of creep cement paste with $30 \%$ fly ash content. On the left the basic creep of the dried paste. On the right is the creep of water-saturated paste.

Basic creep is calculated as the difference of creep of the dried paste and shrinkage of the dried paste. On the other hand, data of creep of water saturated paste are used from measurement on the specimen. Creep of saturated pastes contains the influence of their shrinkage.

The values in the Table 1 are related to the 25 day of measurement. The size of creep is expressed in dimensionless units -milistrains. The basic unit is the meter. The values in graphs are related to units of millimeters. The value of basic creep in the table is the average of measurements on the two specimens and without influence of the shrinkage. Relative values are calculated to the length of bodies of specimens. Creep values are related 
to measurements of two specimens, but with influence of the shrinkage. Positive values in the table reflect the shortening of bodies.

Table 1. Size of creep after 25 days.

\begin{tabular}{|c|c|c|}
\hline $\begin{array}{c}\text { Cement : } \\
\text { fly ash }\end{array}$ & $\begin{array}{c}\text { Basic creep } \\
(\mathbf{m m} / \mathbf{m m} \\
\left.\times \mathbf{1 0}^{-3}\right)\end{array}$ & $\begin{array}{c}\text { Creep } \\
(\mathbf{m m} / \mathbf{m m} \\
\left.\times \mathbf{1 0}^{-3}\right)\end{array}$ \\
\hline $60: 40$ & 0.210 & 1.827 \\
\hline $70: 30$ & 0.256 & 0.803 \\
\hline $50: 50$ & 0.339 & 2.050 \\
\hline $100: 0$ & 0.279 & 1.103 \\
\hline
\end{tabular}

\section{Results of measurements}

Fig. 2 and 3 clearly shows the results of creep, which are listed in Table 1. The result of basic creep of cement pastes containing fly ash is very interesting. The range between the highest and lowest creep is 0.129 milistrain. This is a relatively small margin. The value of creep of pure cement paste is between the values of creep. Cement pastes with fly ash in dry condition achieves low values of creep. Nevertheless, it is evident that with increasing ash content in the cement paste increases the size of creep.

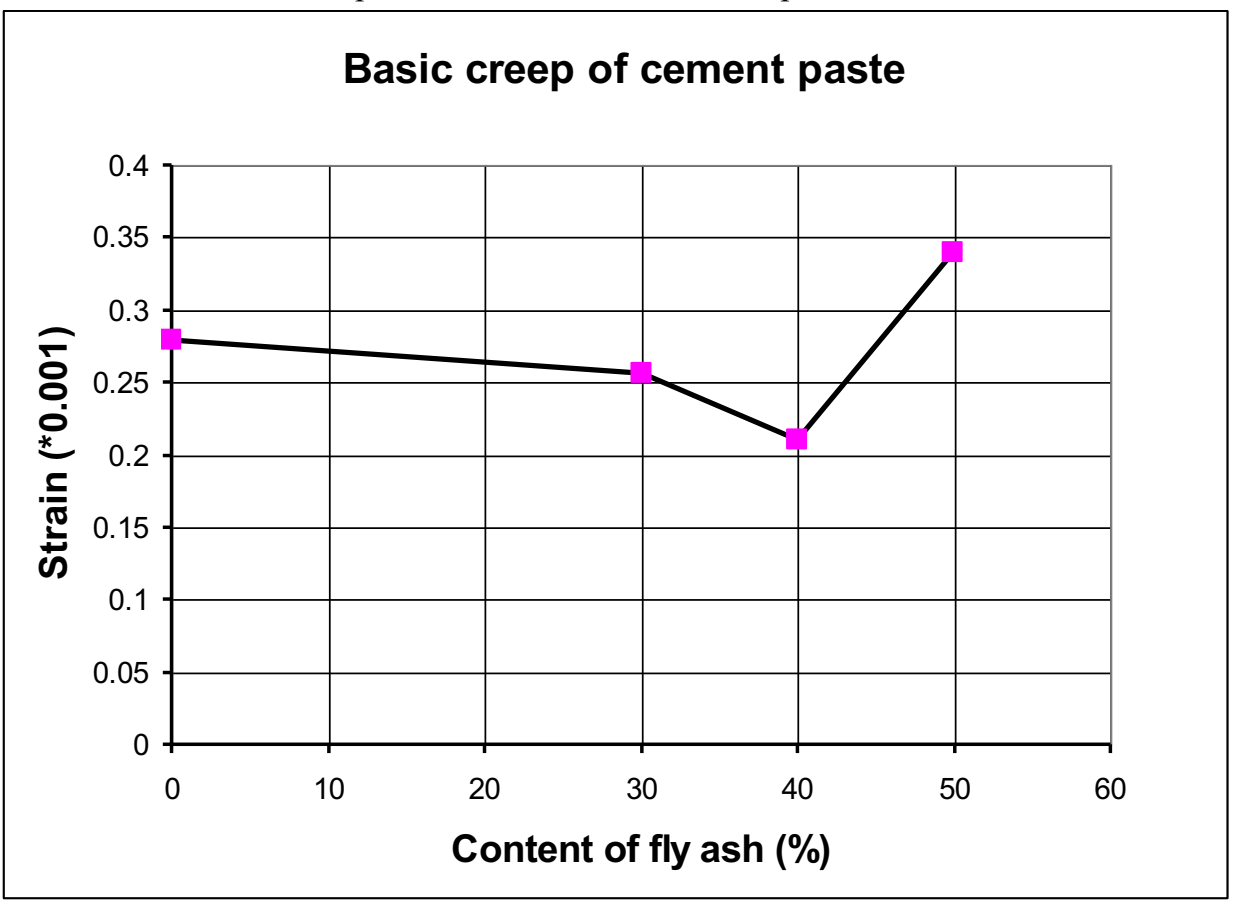

Fig. 2. Results of basic creep of the cement pastes with content of fly ash.

Water saturated cement paste with fly ash reached higher values of creep than the creep of dried pastes. The growth of strain is related to the growth of fly ash content in cement paste. 
Increasing the fly ash content of $20 \%$ has led to an increase of strain by more than $100 \%$. Creep of pure cement paste corresponds to the creep pastes containing $32 \%$ of fly ash.

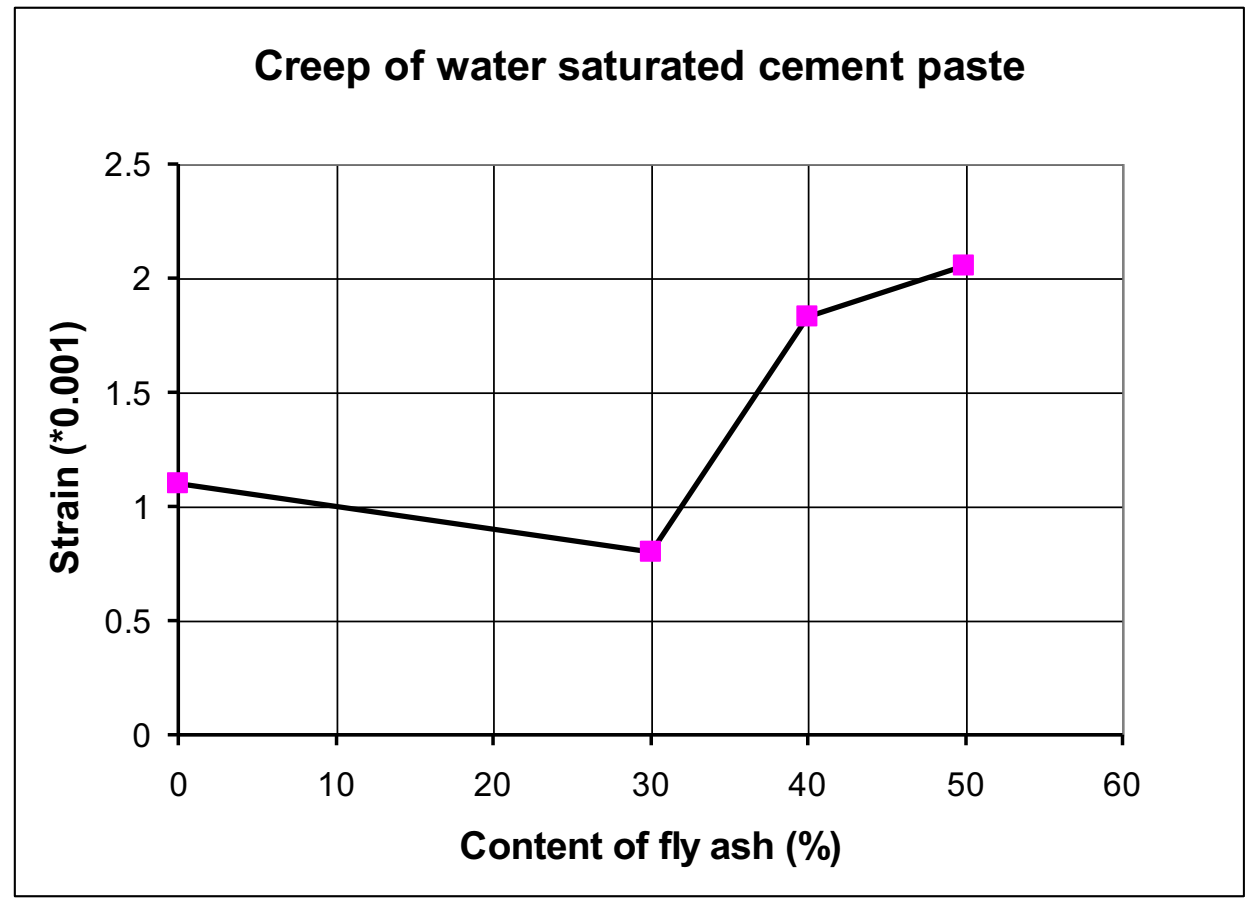

Fig. 3. Results of creep of the water saturated cement pastes with content of fly ash.

\section{Summary}

Enlarging the size of the creep occurs together with increasing fly ash content in the cement paste. Amount of free water has a significant impact on the size of creep. Dried cement paste with fly ash has a small scattering of creep sizes for different amount fly ash in pastes. In contrast, the size of creep of water-saturated cement paste is higher with increasing ash. The most suitable amount of classical ash in the saturated and dried cement paste is $30 \%$.

This work has been supported by project SGS project No.16/201/OHK1/3T/11 "Advanced from design of materials to the constructions".

\section{References}

1. P. Padevět, T. Otcovská, O, Zobal, Variation of Material Properties of Cement Pastes with Various types of Fly Ash During Maturation, WSEAS Transactions on Applied and Theoretical Mechanics 9, 88-96 (2014)

2. D. P. Bentz, E. Schlangen, and E. J. Garboczi, Materials Science of Concrete IV, (edited by J.P. Skalny and S. Mindess, American Ceramic Society, Westerville, OH, pp. 155-200,1994) 